\title{
A Contrastive Analysis of Classroom-Based Language Assessments
}

\author{
Haoran Chen ${ }^{1}$ \\ ${ }^{1}$ Faculty of Arts and Education, Deakin University, Melbourne, Australia \\ Correspondence: Haoran Chen, Faculty of Arts and Education, Deakin University, Melbourne, Australia. \\ E-mail: 2876641722@qq.com
}

Received: March 20, 2020

Accepted: April 24, 2020

Online Published: April 27, 2020

doi: $10.5539 /$ elt.v13n5p110

URL: https://doi.org/10.5539/elt.v13n5p110

\begin{abstract}
Classroom-based language assessments mainly include formative assessment and summative assessment, which are the most commonly used evaluation methods. The present study adopts a contrastive method to analyze the two types of assessments. Results of the study show that: 1) the characteristics of formative assessment contain teachers' adaptation to classes and immediate feedback provided for teachers, while summative assessment, as a high-risk one, needs a high standard control and safety for dependability and effectiveness; 2) formative assessment is suitable for any places with multiple standards for the judgement of learners' achievements while summative assessment evaluates the educational effect or the whole process of special education at a certain time point, and both assessments can always be conducted on network platforms nowadays; 3) evidence and interpretation are taken into consideration in formative assessment and summative assessment respectively while the two types of assessment complement each other for the related teaching goals; 4) more attention may be paid to both assessment for learning (AfL) and assessment as learning $(\mathrm{AaL})$ in the future development of assessment. The contrastive study is expected to provide a reference for classroom-based language teaching and learning.
\end{abstract}

Keywords: contrastive analysis, classroom-based, language assessment

\section{Introduction}

The development of the classroom language assessment project is currently in full swing. The evidence which mainly relates to the development of classroom-based assessment has grown over last decade explaining the importance of language assessment, and an increasing number of people are studying classroom-based language assessment (Rea-Dickins, 2008). Leung (2005) points out that classroom-based assessment is that teachers gather and use the information about students' language performance in general classroom activities to decide their teaching process. Classroom-based language assessments are mainly divided into two categories: formative assessment and summative assessment (Scriven, 1967), both of which can be designed and conducted online in the society with highly developed information technology (Wang, et al., 2006; Cassady \& Gridley, 2005; Liu, 2013; Liu, 2017). A contrastive method will be adopted in the present study, with the aim to examine the distinctions between formative assessment and summative assessment from the following aspects: characteristics, conditions, teachers' considerations. Meanwhile, we will discuss the current issues of classroom-based language assessments. It is of great importance to provide the reference for language teachers to choose appropriate assessment in the teaching process.

\section{Characteristics of Classroom-based Language Assessments}

During the process of assessment, summative assessment is presented in a single way (Taras, 2009). Summative assessment is defined as the evaluation of student language learning at the conclusion of a defined instructional period by three major criteria: tests, assignments, or projects used to determine whether students have learned what they were expected to learn; generally evaluative, rather than diagnostic; assessment results often recorded as scores or grades. (Note 1) However, formative assessment, as a plus process of summative assessment, can be defined as "diagnostic use of assessment to provide feedback to teachers and students over the course of instruction" (Boston, 2002), requiring feedback to indicate the gap related to criteria or standards. In the end, these kinds of information must be used by learners in the future activities. Summative assessment may be presented in an implicit form, and formative assessment is explicit, or both can be explicit (Taras, 2009). 


\subsection{Characteristics of Formative Assessment}

In formative assessment, teachers often adapt themselves to their classes, varying "in terms of both their scope (e.g. the number of students involved) and time-scale" (Wiliam \& Black, 1996). In a large-scope class (e.g. 40 students), a teacher decides students' practice of English speaking in 4-member groups. Formative assessment can be conducted in groups by the teacher. In terms of time-scale, the teacher may use the "referential group" students to judge the speed of his/her class when he/she faces to the whole class. However, the group reference way is not suitable for a small-scope class (e.g. 10 students). On the contrary, a teacher may be immediately adapted to deal with other aspects of the student's face or body language when he/she practices oral English with an individual student. This adaptability may appear in the context of teaching on a shorter time scale. If he/she wants to conduct formative assessment of the whole class, the teacher attaches importance to all the ten students' feedback. Therefore, the function of formative assessment is verified in terms of its consequences and its implications.

Formative assessment in teaching depends usually on trying to provide teachers with a precise calculating of students' capacity at a specific time point in the class, or to provide assessment tasks which are similar to summative tests for students. This can make students recognize benefits and drawbacks, and better plan the real test. The effectiveness of formative assessment depends in part on the way in which feedback is provided to learners. The ideal feedback method seems to be a timely performance report that can provide feedback immediately after the whole test or test is finished.

\subsection{Characteristics of Summative Assessment}

When it comes to summative assessment, there will be some features different from formative assessment. Not only are summative assessments rated, but the testing methods and students' feedback methods are also different.

On the one hand, summative assessment, a type of accumulative assessment, is almost always graded to get a less frequent final assessment of what has been really learned (Dixson \& Worrell, 2016). It is used to test how much has been studied for the final assessment. It is almost always scored, usually less frequently, and appear in the end of the teaching section. Examples of summative assessments are final examination, university entrance exam, final student performance and semester thesis. Normally, if the student's performance is well-pleasing, the assessment target will not be more formalized after the summative assessment, unless it is a cumulative end-of-year exam. Excepting for the function of ensuring the level of success or proficiency of a student at a specific time period, summative assessments are also used to determine eligibility for a course.

On the other hand, being different from formative assessment which is often used to provide students and teachers with feedback, summative assessment is often high-risk assessment in that feedback is not focus. As for high-risk assessment, taking an online summative assessment (Cassady \& Gridley, 2005) as an example, summative assessment is different in form from formative assessment and it also performs different functions from those in formative assessment. Summative assessment focuses on technological problems in the process of testing, and ensures the online testing nature to avoid some negative effect on learners' actual performance, especially learners' anxiety over the online summative assessment should be decreased. An added advantage of an online summative assessment is that the extra classroom time can be available in traditional campus courses, in which teachers can spend, rather than class time, extra time on the instruction for students. Meanwhile, summative assessment, not concentrating on feedback, will not only provide opportunities for students to show their understanding of the main concept but also offer students with the opportunity to think critically about when applying their understanding to settle new issues or explain new phenomena under new conditions (Dixson \& Worrell, 2016).

\section{Conditions for Assessments}

\subsection{Suitable Conditions for Formative Assessment}

Formative assessment is suitable for any places where multiple standards are used to judge the quality of a student's answers (Sadler, 1989). A key factor in formative assessment is feedback, and it is usually defined by messages relating to what has been or is being done, i.e. "information about the gap between the actual level and the referenced level" (Ramaprasad, 1983). If the teacher simply records the student's performance during the classroom assessment process and passes it to a third party or teacher who does not change the knowledge, the results will deviate from the basic judgment and standard (Sadler, 1989). Therefore, teachers must carefully capture effective information in the process of formative assessment. In evaluating the quality of a student's task or manifestation, the instructor must have a quality concept appropriate to the task and be able to decide the student's task related to the notion. Formative assessment covers feedback and self-monitoring and the aim of 
many teaching systems is to promote the interim from feedback to self-monitoring (Sadler, 1989).

Currently, formative assessment may be achieved on network platforms, which is the most suitable condition. In the experiments, Wang, et al. (2006) tested the impact of the formative assessment of online classes on students' achievements. This experiment involved 455 seventh-grade students from six middle schools. They developed a web-based course called BioCAL that combines three different formative assessment methods, which concludes formative assessment module for web-based assessment and test analysis systems, normal modules for web-based assessment and test analysis systems, and paper and pencil testing. The analysis concluded that a learning environment with formative assessment brings many benefits to learners and emphasized the positive outcomes of combining e-learning environments with web-based assessments. In Guangdong University of foreign Studies (GDUFS), formative assessment is conducted on FiF Teaching Assessment System (FiF Platform) (FiF is the abbreviation from the slogan "For Ideal Future"), which is a multi-terminal online teaching management system based on the concept of formative assessment (Chen, 2017). FiF Platform is an e-Portfolio assessment platform used to achieve students' autonomy in their learning of college English courses in that the Platform has four functional modules (curriculum module, teaching module, students' portfolio module and teaching diary module) and four characteristics (formative assessment; student-centered; connection between teaching activities in classroom and beyond and accumulation of students' scores).

As for online assessment, students can participate at any time, and teachers can conduct repeated evaluations and provide timely feedback to help compensate for the weaknesses of students' learning ability. After all, various types of assessments are ultimately for the students' learning ability. Repetitive testing is a significant device for network-based formative assessment strategies. However, this kind of tactics must be combined with the function of non-response and timely feedback to facilitate the formation of the network. In order to make feedbacks valid, teachers need to provide the early learning process and direction to enhance students' performance.

\subsection{Suitable Conditions for Summative Assessment}

Summative assessment involves the learners' assessment, and judge their progress at certain time point of the course via feedback and scoring (McCarthy, 2015). The key point of summative assessment is the result of task, and attempts to supervise educational achievement. It is considered to be assessment of learning (AoL), not as formative assessments.

As a traditional method for evaluating learners' achievements, summative assessment is relatively picky about its conditions. With a high generalization level and a wide range of test contents, it is an important way to evaluate the educational effect or the whole process of special education and to determine whether these efforts have achieved the predetermined educational goals, for example, to test the development degree of learners' comprehensive language ability in mid-term examinations, final examinations, term papers, or college entrance examinations etc. Therefore, this kind of phased terminal assessment is also known as post-assessment, stage assessment or post-education assessment.

Nowadays, summative assessment can always be conducted on network platforms, which is often one of the most suitable ways in the present network information era. Different online formative assessment, "summative assessment process requires high levels of control and security in the testing process to ensure reliability and validity in scores, attention to technical problems that may arise during the testing session, and assurance that the online nature of the testing process itself has no impact on actual performance (Cassady \& Gridley, 2005)." For example, McCarthy (2015) explored three types of summative online feedback models in the Media Arts and Design Language course at the University of South Australia in Australia, i.e. written feedback, audio feedback and video feedback. To be specific, they used audio, video, and written feedback to confirm the strengths and weaknesses of each model and made sure which pattern gives students a deeper understanding of their language performance, and which model makes summative assessment the most effective. Taking China's Test for English Ability as another example, the English test, a typical summative assessment, will be designed and conducted based on China Standards of English (CSE). (Note 2) The national English test, which will be implemented online, is a series of multi-level, coherent and orderly one with the evaluation of learners' ability of comprehensive language use. Meanwhile it will timely integrate the existing English tests and reform the testing content and forms to meet the diversified needs for graduation, promotion, employment, and going abroad.

\section{Considerations for Teachers in Conducting Formative and Summative Assessments}

From the historical view, many assessment studies are based on substances and methods of psychology, most of which can handle psychological characteristics and their measurement (James, 2006). Therefore, the classic evaluation methods are based on the individual, and the focus is on the process of investigating students' certain 
behaviors or qualities rather than what has been acquired. Recently, more and more attention has been paid to how learning occurs. Language learning is not only considered as a personal activity, but interpersonal interactions and intermediary tools such as language are now seen as playing a vital role during learning. Therefore, the assessment of learning achievements requires more consideration of the social processes and individual processes in which learning takes place (James, 2006).

While conducting formative assessment, teachers particularly take each of their students' language development into consideration. Evidence of a student's daily performance, as one of three key dimensionalities of assessment (Hill \& McNamara, 2011), should be gathered for teachers to make judgements in the process of formative assessment. However, teachers' consideration lies in the language performance of the whole group while making summative assessment. On the interpretation dimension (Hill \& McNamara, 2011), teachers always relate the results from summative assessment to the reliability and validity, with the purpose to upgrade their teaching or improve students' learning.

Whether using formative or summative assessments, Dixson and Worrell (2016) argue that the two types complement each other in that the former can be used throughout students' learning process while the latter used at a certain period for evaluate students' achievements. As for assessment implemented, Hill and McNamara (2011) identify four key steps which are planning, framing, conducting and using assessment. At the first step, planning mainly relates to analyzing inner syllabus files and discussing what is taught and assessed with and between teacher participants. For the second step, the framing assessment mainly examines how (or whether) a learner in his/her class knows about a certain learning activity assessed. In the third step, conducting assessment includes clear, arranged, formal activities, as well as less obvious, unarranged, instruction-embedded activities. As the fourth step, assessment data is used for such five purposes as 'teaching', 'learning', 'reporting', 'management' and 'socialization'.

\section{Current Issues of Classroom-based Language Assessments}

One of the recent discussions on assessments has emerged as a new concept, assessment for learning (AfL) in formative assessment, differentiated from AoL in summative assessment (Hill \& McNamara, 2011). During the process of AfL, learning itself is a goal, and assessment is the means to achieve the goal (Lee, 2007). In carrying out AfL, teachers require to integrate teaching, learning, and assessment rather than focusing on how to assess student's performance itself. AfL emphasizes the critical role that assessment plays in strengthening and expanding students' independent learning. The implementation of AfL begins with an understanding of the connection between teaching and learning, and in particular how to use assessments to inform teaching and learning. Therefore, researchers currently pay special attention to effective planning of teaching and learning, AfL be recognized as central to classroom practice, what learners perform be observed (Gardner, 2002), and so on.

The other trend is to treat assessment as learning (AaL) in formative assessment (Earl \& Katz, 2006; Hill \& McNamara, 2011). AaL highlights the importance of the self-monitoring processes students use during learning, which originates from the thought that learners restructure their cognition in the process of the interaction with new ideas (Earl \& Katz, 2006). As for AaL, researchers focus mainly on teacher's role, student's role and teacher's planning assessment and so on. Different from that in AoL, teacher's role in AaL is extended to design instruction and assessment for "all students to think about and monitor their own learning"; students play their roles as independent learners; planning assessment includes why something is assessed, what is assessed, how to ensure reliability and validity of assessment, etc. (Earl \& Katz, 2006).

\section{Conclusion}

By reviewing the above information about the two types of classroom-based language assessments, the present study conducts a contrastive analysis of the characteristics of and the evaluation conditions for the two methods, points out the important considerations for teachers in conducting formative and summative assessments, and current issues of classroom-based language assessments. The contrastive study is expected to provide a reference for classroom-based language teaching and learning. In the future development of assessment, the study also shows that more attentions may be paid to both AfL and AaL.

\section{Acknowledgments}

I would like to thank the three anonymous reviewers for their insightful comments and valuable suggestions.

\section{References}

Boston, C. (2002). The Concept of Formative Assessment. Practical Assessment, Research, and Evaluation, 8(1), 1-4. https://doi.org/10.7275/kmcq-dj31 
Cassady, J. C. \& Gridley, B. E. (2005). The effects of online formative and summative assessment on test anxiety and performance. The Journal of Technology, Learning and Assessment, 4(1), 4-30. https://ejournals.bc.edu/index.php/jtla/article/view/1648

Chen, J. (2017). An e-Portfolio-based Model for the Application and Sharing of College English ESP MOOCs. Higher Education Studies, 7(2), 35-42. https://doi.org/10.5539/hes.v7n2p35

Dixson, D. D. \& Worrell, F. C. (2016). Formative and summative assessment in the classroom. Theory into practice, 55(2), 153-159. https://doi.org/10.1080/00405841.2016.1148989

Earl, L. \& Katz, S. (2006). Rethinking Classroom Assessment with Purpose in Mind. Winnipeg, Manitoba: Western Northern Canadian Protocol.

Gardner, J. (2002). Assessment for Learning: 10 Principles. Institute of Education, London: Unknown Publisher.

Hill, K. \& McNamara, T. (2011). Developing a comprehensive, empirically based research framework for classroom-based assessment. Language Testing, 29(3), 395-420. https://doi.org/10.1177/0265532211428317

James, M. (2006). Assessment, teaching and theories of learning. Assessment and learning, 47, 60. https://doi.org/10.13140/2.1.5090.8960

Lee, I. (2007). Assessment for learning: Integrating assessment, teaching, and learning in the ESL/EFL writing classroom. Canadian Modern Language Review, 64(1), 199-213. https://doi.org/10.3138/cmlr.64.1.199

Leung, C. (2005). Classroom teacher assessment of second language development: Construct as practice. In E. Hinkel (Ed), Handbook of Research in Second Language Teaching and Learning (pp. 869-888). Mahwah: Lawrence Erlbaum Associates, Publishers.

Liu, J. (2013). Modern educational technology and language testing. Computer-Assisted Foreign Language Education in China, (4), 46-51.

Liu, J. (2017). China's Standards of English and Its Applications in English Learning. Foreign Languages in China, 14(6), 4-11. https://doi.org/10.13564/j.cnki.issn.1672-9382.2017.06.002

McCarthy, J. (2015). Evaluating written, audio and video feedback in higher education summative assessment tasks. Issues in Educational Research, 25(2), 153-169.

Ramaprasad, A. (1983). On the definition of feedback. Behavioral Science, 28(1), 4-13. https://doi.org/10.1002/bs.3830280103

Rea-Dickins, P. (2008). Classroom-based language assessment. In E. Shohamy \& N. H. Hornberger (Eds.), Encyclopedia of language and education, 2nd Edition, Volume 7: Language Testing and Assessment (pp. 257-271). New York: Springer.

Sadler, D. R. (1989). Formative assessment and the design of instructional systems. Instructional science, 18(2), 119-144. https://doi.org/10.1007/BF00117714

Scriven, M. (1967). The Methodology of Evaluation. In R. Tyler, R. Gagne \& M. Scriven (Eds.), Perspectives on curriculum evaluation (pp. 39-83). AERA: Monograph Series on Curriculum Evaluation 1. Chicago: Rand McNally.

Taras, M. (2009). Summative assessment: The missing link for formative assessment. Journal of further and Higher Education, 33(1), 57-69. https://doi.org/10.1080/03098770802638671

Wiliam, D. \& Black, P. (1996). Meanings and consequences: a basis for distinguishing formative and summative functions of assessment? British educational research journal, 22(5), 537-548. https://doi.org/10.1080/0141192960220502

Wang, K. H., Wang, T. H., Wang, W. L. \& Huang, S. C. (2006). Learning styles and formative assessment strategy: enhancing student achievement in Web-based learning. Journal of computer assisted learning, 22(3), 207-217. https://doi.org/10.1111/j.1365-2729.2006.00166.x

\section{Copyrights}

Copyright for this article is retained by the author(s), with first publication rights granted to the journal.

This is an open-access article distributed under the terms and conditions of the Creative Commons Attribution license (http://creativecommons.org/licenses/by/4.0/). 